\title{
FERRO - UM ELEMENTO QUÍMICO ESTRATÉGICO QUE PERMEIA HISTÓRIA, ECONOMIA E SOCIEDADE
}

\author{
Hélio A. Duarte*,a, \\ aDepartamento de Química, Instituto de Ciências Exatas, Universidade Federal de Minas Gerais, Campus Pampulha, 31270-901 \\ Belo Horizonte -MG, Brasil
}

Recebido em 12/06/2019; aceito em 26/08/2019; publicado na web em 14/11/2019

\begin{abstract}
IRON - A STRATEGIC CHEMICAL ELEMENT THAT PERMEATES HISTORY, ECONOMY AND SOCIETY. Iron is the 4th most abundant element on the earth crust and it has an important role in several geochemical and biological processes. The importance of the steel for the industrial development of a country makes the iron ore extraction a strategic input responsible for part of the world commerce. Brazil is one of the largest iron ore producers in the world: actually, it is a primary commodity and one of the most important items of its exports. In the present paper, the main sources of iron, how it is available in the nature, its occurrence, its processing and the steel production will be presented. A critical analysis of its importance for the economical and social development of the country will be briefly discussed.
\end{abstract}

Keywords: iron; mineral; mining; commodity; steel; occurrence.

\section{FERRO - UM ELEMENTO QUÍMICO ONIPRESENTE}

Dentre os oito elementos químicos mais abundantes na crosta terrestre, o ferro figura em quarto lugar com cerca de 5\% em massa. Os outros elementos são oxigênio $(46,6 \%)$, silício $(26,72 \%)$, alumínio $(8,13 \%)$, cálcio $(3,63 \%)$, sódio $(2,83 \%)$, potássio $(2,59 \%)$ e magnésio $(2,09 \%)$. Esses elementos correspondem aproximadamente a $97,59 \%$ da massa da crosta terrestre. É possível, pois, inferir que a crosta terrestre é formada principalmente por compostos de oxigênio na forma de óxidos, hidróxidos e aluminosilicatos.

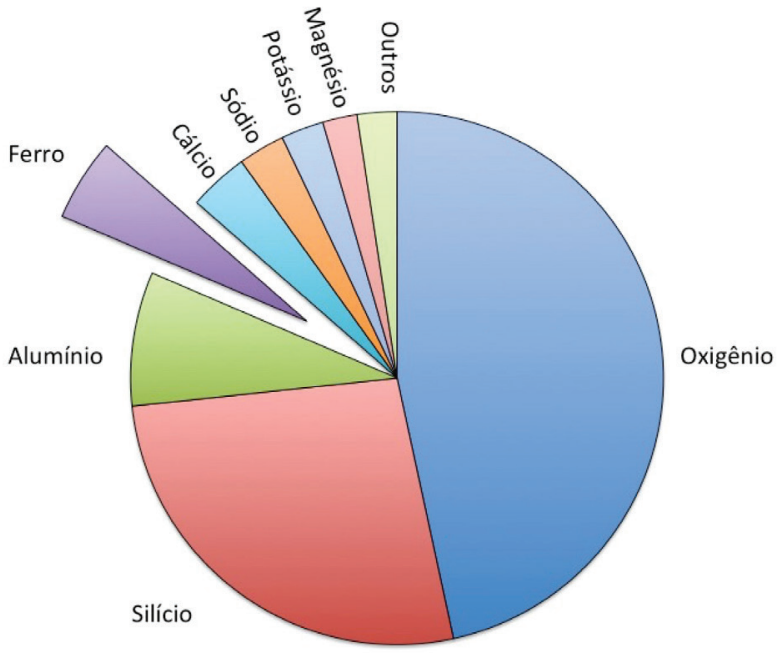

Figura 1. Distribuição dos elementos químicos na crosta terrestre. ${ }^{1}$ Em destaque o seguimento relativo à proporção de Ferro

O ferro é um elemento ubíquo na crosta terrestre. Pode ser encontrado em grandes jazidas, na forma de minerais com teores extremamente variáveis mesmo como elemento traço. $\mathrm{O}$ ferro apresenta propriedades químicas e físicas que o faz importante em processos químicos e físicos, no ambiente mineral e nos sistemas biológicos.

O elemento ferro apresenta configuração eletrônica $[\mathrm{Ar}] 4 \mathrm{~s}^{2} 3 \mathrm{~d}^{6}$ e dois números de oxidação (NOx) mais comuns, $2+$ e $3+$, com as

*e-mail: duarteh@ufmg.br configurações eletrônicas $[\mathrm{Ar}] 3 \mathrm{~d}^{6} \mathrm{e}[\mathrm{Ar}] 3 \mathrm{~d}^{5}$, respectivamente. O raio iônico varia entre $0,63-0,78 \AA$, conforme a simetria do campo cristalino. A presença de orbitais "d" parcialmente preenchidos permite uma variação grande da energia de estabilização do campo cristalino, em função do NOx, dos ligantes ao redor do centro metálico e do número de coordenação.

Para se compreender melhor a importância do ferro e da sua capacidade de modular vários processos químicos, biológicos e geoquímicos, é preciso analisar a sua reatividade em meio aquoso. A Tabela 1 mostra algumas das propriedades dos íons de ferro em meio aquoso. $\mathrm{O} \mathrm{Fe}^{3+}$ é um ácido relativamente forte com pKas 2,2; 3,5; 6,3 e 9,6. Em meio aquoso e pH abaixo de 2,2; o Fe ${ }^{3+}$ é melhor modelado como a espécie hexaaqua de ferro (III), $\left[\mathrm{Fe}\left(\mathrm{H}_{2} \mathrm{O}\right)_{6}\right]^{3+}$. Aumentando-se o $\mathrm{pH}, \mathrm{o} \mathrm{Fe}^{3+}$ hidrolisa-se para formar espécies como $\mathrm{Fe}(\mathrm{OH})^{2+}(\mathrm{aq})$, $\mathrm{Fe}(\mathrm{OH})_{2}{ }^{2+}(\mathrm{aq}), \mathrm{Fe}(\mathrm{OH})_{3}(\mathrm{aq})$ e $\mathrm{Fe}(\mathrm{OH})_{4}{ }^{-}(\mathrm{aq})$. Por outro lado, o íon $\mathrm{Fe}^{2+}$ é um ácido fraco com pKa em torno de 9,2. Além disso, a solubilidade do $\mathrm{Fe}^{2+}$ é $0,72 \mathrm{~g} / 100 \mathrm{~mL}\left(\mathrm{Kps}=4,87 \times 10^{-17}\right)$, enquanto o $\mathrm{Fe}^{3+}$ é insolúvel em água $\left(\mathrm{Kps}=2,79 \times 10^{-39}\right)$. Não obstante a versatilidade da química do ferro em meio aquoso tanto no que se refere especiação química, quanto aos processos de dissolução ou de precipitação, é preciso comentar ainda sobre as suas propriedades eletroquímicas. $\mathrm{O}$ potencial eletroquímico padrão de redução do ferro é $0,77 \mathrm{~V}$, ou seja, o $\mathrm{Fe}^{3+}(\mathrm{aq})$ tende a ser reduzido a $\mathrm{Fe}^{2+}(\mathrm{aq})$ nas condições padrão. A sua posição intermediária na tabela de potencial de redução indica que o equilíbrio eletroquímico pode ser facilmente deslocado em função das condições do meio, ou seja, em função do $\mathrm{pH}$, da concentração e da presença de outros íons.

O ferro, no ambiente aquoso e oxigenado - como é o caso da crosta terrestre - apresenta uma química rica, em que intrincados processos podem ocorrer e deslocar o equilíbrio químico, de forma a solubilizar e ressolubilizar materiais, promover reações e transportar elétrons por meio de reações de oxirredução. A Figura 2 apresenta o diagrama Eh x pH (diagrama de Pourbaix) para o ferro, em condição de metaestabilidade. As fases mais estáveis termodinamicamente, como hematita, $\alpha-\mathrm{Fe}_{2} \mathrm{O}_{3}$, e magnetita, $\mathrm{Fe}_{3} \mathrm{O}_{4}$, foram retiradas do diagrama. Observa-se que o $\mathrm{Fe}^{2+}$ é predominante em ambiente anóxico e pH ácido a circum-neutro. Em pH mais alto, observa-se a formação de $\mathrm{FeOH}^{+}$e $\mathrm{Fe}(\mathrm{OH})_{2}$ (s). Em ambiente aerado e $\mathrm{pH}$ baixo, o $\mathrm{Fe}^{3+}(\mathrm{aq})$ é predominante. Os oxi-hidróxidos de ferro amorfos ou cristalinos, nesse último caso como a goethita, $\alpha-\mathrm{FeOOH}$, ou hematita, são formados 
Tabela 1. Propriedades dos íons de ferro em meio aquoso

\begin{tabular}{|c|c|}
\hline Hidrólise do $\mathrm{Fe}^{3+}(\mathrm{aq})$ & $\mathrm{pKa}^{1}$ \\
\hline $\mathrm{Fe}^{3+}(\mathrm{aq})+\mathrm{H}_{2} \mathrm{O}=[\mathrm{Fe}(\mathrm{OH})]^{2+}(\mathrm{aq})+\mathrm{H}^{+}(\mathrm{aq})$ & 2,2 \\
\hline$[\mathrm{FeOH}]^{2+}(\mathrm{aq})+\mathrm{H}_{2} \mathrm{O}=\left[\mathrm{Fe}(\mathrm{OH})_{2}\right]^{+}(\mathrm{aq})+\mathrm{H}^{+}(\mathrm{aq})$ & 3,5 \\
\hline$\left[\mathrm{Fe}(\mathrm{OH})_{2}\right]^{+}(\mathrm{aq})+\mathrm{H}_{2} \mathrm{O}=\left[\mathrm{Fe}(\mathrm{OH})_{3}\right](\mathrm{aq})+\mathrm{H}^{+}(\mathrm{aq})$ & 6,3 \\
\hline$\left[\mathrm{Fe}(\mathrm{OH})_{3}\right](\mathrm{aq})+\mathrm{H}_{2} \mathrm{O}=\left[\mathrm{Fe}(\mathrm{OH})_{4}\right]^{-}(\mathrm{aq})+\mathrm{H}^{+}(\mathrm{aq})$ & 9,6 \\
\hline Hidrólise do $\mathrm{Fe}^{2+}(\mathrm{aq})$ & $\mathrm{pKa}^{1}$ \\
\hline $\mathrm{Fe}^{2+}(\mathrm{aq})+\mathrm{H}_{2} \mathrm{O}=[\mathrm{Fe}(\mathrm{OH})]^{+}(\mathrm{aq})+\mathrm{H}^{+}(\mathrm{aq})$ & 9,2 \\
\hline \multicolumn{2}{|l|}{ Solubilidade $^{2}$} \\
\hline $\mathrm{Fe}(\mathrm{OH})_{3}(\mathrm{~s}) \quad \mathrm{Kps}=\left[\mathrm{Fe}^{3+}\right][\mathrm{OH}]^{3}=2,79 \times 10^{-39}$ & Insolúvel \\
\hline $\mathrm{Fe}(\mathrm{OH})_{2}(\mathrm{~s}) \quad \mathrm{Kps}=\left[\mathrm{Fe}^{2+}\right][\mathrm{OH}]^{2}=4,87 \times 10^{-17}$ & $0,72 \mathrm{~g} / 100 \mathrm{~mL}$ \\
\hline Potencial padrão de redução do Ferro ${ }^{2}$ & $\varepsilon^{\circ}(\mathrm{V})$ \\
\hline $\mathrm{Fe}^{3+}(\mathrm{aq})+e^{-} \rightarrow \mathrm{Fe}^{2+}(\mathrm{aq})$ & 0,771 \\
\hline
\end{tabular}

${ }^{1}$ Ref. $2 ;{ }^{2}$ Ref. 3 .

em $\mathrm{pH}$ mais alto e em ambientes aerados. A magnetita, constituída de formas de ferro di- e trivalente, é formada em condições de Eh intermediário. No processo de desidratação, a goethita se transforma em hematita. A água e a presença de oxigênio modulam a distribuição das várias espécies químicas de ferro e, consequentemente, o seu comportamento químico na natureza. ${ }^{4}$

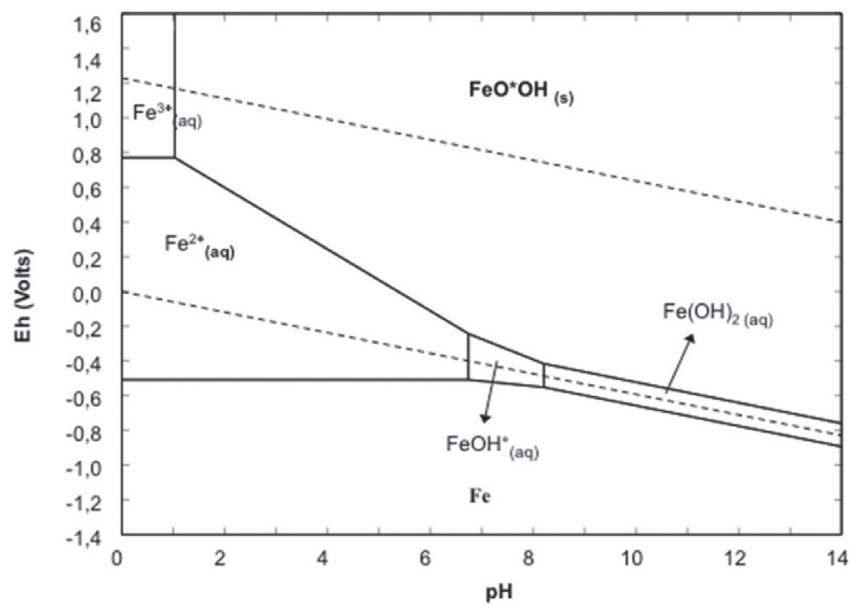

Figura 2. Diagrama de Pourbaix para o sistema $\mathrm{Fe}-\mathrm{H}_{2} \mathrm{O}$, a $25^{\circ} \mathrm{C}$, mostrando as espécies metaestáveis sólidas $\mathrm{FeOOH}$ e $\mathrm{Fe}(\mathrm{OH})_{2}$ em equilíbrio com as espécies aquosas. As fases mais estáveis termodinamicamente, como $\mathrm{Fe}_{2} \mathrm{O}_{3}$ e $\mathrm{Fe}_{3} \mathrm{O}_{4}$, foram retiradas do diagrama. $[\mathrm{Fe}]=0,1 \mathrm{~mol} \mathrm{~L} \mathrm{~L}^{-1}$. A região de estabilidade da água está limitada pelas linhas paralelas e tracejadas

Nas condições fisicoquímicas encontradas na Terra, o ferro apresenta versatilidade, podendo interagir e formar compostos diferentes, participar em processos de mobilidade de íons no meio ambiente, formar sólidos, promover reações de redox, entre outros. Algumas dessas reações têm grande influência na mobilidade de diversas espécies no meio ambiente. Processos naturais, frequentemente mediados por microrganismos, modulam a predominância de $\mathrm{Fe}^{3+}$ ou $\mathrm{Fe}^{2+} \mathrm{e}$, assim, favorecem a coprecipitação/adsorção de espécies químicas, como o arsênio, por exemplo, em oxi-hidróxidos de ferro ou a sua dissolução/dessorção, com consequente mobilização para o meio ambiente. Em sistemas biológicos, o ferro tem papel de suma importância em vários processos bioquímicos, como nas reações enzimáticas, no transporte de oxigênio e de elétrons.

A abundância do ferro, a relativa facilidade para a sua obtenção na forma de $\mathrm{Fe}(\mathrm{s})$, as suas propriedades mecânicas como maleabilidade, resistência e a sua fácil conformação o tornaram material de base para a fabricação de ferramentas e equipamentos. As propriedades mecânicas do ferro podem ser controladas em função da presença de carbono, níquel, cromo, silício, entre outros. O aço, por exemplo, é uma liga que contém cerca de $0,5-1,7 \%$ de carbono. Em função da proporção de carbono e do tratamento térmico aplicado, o aço adquire propriedades que são adequadas para diferentes aplicações. Por isso, o ferro é encontrado na grande maioria dos utensílios e ferramentas que utilizamos. Podemos dizer que desde a Era do Ferro, há cerca de 1200-300 A.C., o ferro sempre esteve presente ao longo da história da humanidade. No nosso dia-a-dia, o ferro é encontrado em quase tudo que utilizamos, como em parafusos, utensílios de cozinha, ferramentas, transporte motorizado, máquinas, material de construção, navios, concreto armado dos viadutos, prédios e construções, nos aviões e em outras inúmeras aplicações.

Nos tempos mais remotos, o ferro foi utilizado no desenvolvimento de ferramentas para auxiliar nas tarefas básicas na agricultura, na caça, na guerra e no transporte. A sua importância é ampliada durante a expansão marítima por volta do século XV e, principalmente, com a Revolução Industrial, nos fins do século XVIII à primeira metade do século XIX

No Brasil, a exploração incipiente do minério de ferro remonta ao ciclo do ouro com a necessidade de se produzir insumos para a agricultura e a própria extração do ouro. ${ }^{5}$ Naquela época, a produção era local, doméstica e voltada para o próprio uso. O marco da produção moderna de aço no Brasil pode ser considerado a inauguração da Companhia Siderúrgica Belgo-Mineira em 1921, ${ }^{6}$ e a produção de aço inoxidável pela Acesita (ora nomeada Aperam) ${ }^{7}$ em 1944. A Companhia Vale do Rio Doce, CVRD (ora nomeada VALE), foi criada em 1942, pelo presidente Getúlio Vargas, com o objetivo de ampliar a exploração do minério de ferro e de outras riquezas minerais. A CVRD contou com a colaboração dos Estados Unidos e da Inglaterra em um processo de aproximação devido à conjuntura da Segunda Guerra Mundial. A criação da Companhia Siderúrgica Nacional (CSN), em 1941, é também um marco no desenvolvimento da siderurgia brasileira, como fruto da preocupação de atender as necessidades do desenvolvimento econômico e da soberania nacional, na confecção de armas e veículos. ${ }^{8}$

A produção de aço está ligada à abundância de jazidas de ferro na natureza, da disponibilidade de carvão (vegetal ou mineral), usado como redutor no processo de redução química, e de energia (eletricidade). A importância do aço para o desenvolvimento industrial de um país torna a matéria prima de onde se extrai o ferro um insumo responsável por parte do comércio mundial e estratégico para o desenvolvimento dos países. A produção em larga escala do minério de ferro voltada para o comércio internacional, cujo preço é definido pela oferta e procura, o torna uma commodity mineral. O Brasil, como um dos maiores produtores de minério de ferro, é um player importante no comércio mundial. O minério de ferro é um dos insumos mais importantes da pauta de exportações e responde por cerca de $8,8 \%$ das exportações brasileiras. ${ }^{9}$

Serão apresentadas, neste artigo, as principais fontes de ferro, como ele se apresenta na natureza e a sua importância econômica e uma breve discussão sobre o desenvolvimento científico e tecnológico na produção de minério de ferro e a produção de aços especiais como estratégia para o desenvolvimento social e econômico de nosso país.

\section{O MINÉRIO DE FERRO}

O ferro é encontrado na natureza principalmente na forma de óxidos, hidróxidos e oxi-hidróxidos, geralmente, na forma cristalina. Minério é um material natural contendo um conjunto de minerais do qual se pode extrair um ou mais minerais de interesse, de forma 
economicamente viável. A parte do minério que não tem valor econômico é chamado de ganga.

Os principais minerais presentes no minério de ferro são hematita, goethita e magnetita. ${ }^{10}$ Há vários outros minerais de ferro que são encontrados na natureza, mas não têm interesse econômico para a extração do ferro. No entanto, isso não quer dizer que eles não tenham interesse científico e tecnológico. A akaganeita, -FeOOH, por exemplo, foi recentemente utilizada como material catódico em baterias de lítio recarregáveis. ${ }^{11}$

A pirita, $\mathrm{FeS}_{2}$, é o sulfeto mineral mais abundante, geralmente associada a minérios contendo metais como cobre, urânio e ouro. Ao ser descartada durante a extração desses metais, a pirita pode ser oxidada através da exposição ao meio ambiente, formando ácido sulfúrico e íon férrico (oxidante), o que pode levar à acidificação de aquíferos, promover a solubilização de rochas e, consequentemente, a mobilização de metais e outros elementos tóxicos associados ao minério. Esse fenômeno, chamado de drenagem ácida de rocha (DAR) ou drenagem ácida de mina (DAM), é considerado a principal preocupação ambiental em regiões com mineração de sulfetos metálicos. ${ }^{12}$ Em algumas regiões do planeta, a pirita é utilizada como fonte de ferro. A importância do controle da DAM/DAR é de suma importância e merece nossa atenção, uma vez que afeta a viabilidade econômica e gera impactos ambientais e sociais de empreendimentos na área de mineração.

\section{Hematita - $\alpha-\mathrm{Fe}_{2} \mathrm{O}_{3}$}

A hematita, $\alpha-\mathrm{Fe}_{2} \mathrm{O}_{3}$, apresenta grupo pontual do tipo $R 3 c$, cuja formação de células unitárias do tipo hexagonal (romboédrica), contém 6 fórmulas químicas por célula unitária. Para a estrutura hexagonal, têm-se parâmetros de rede $a=b=5,03 \AA$ e $c=13,75 \AA{ }^{13}$ Em ambas as estruturas ocorre uma periodicidade de simetria de spin, em arranjo antiferromagnético ao longo dos planos basais da hematita em temperatura abaixo de $250 \mathrm{~K}$. Em temperatura ambiente, a hematita apresenta caráter fracamente ferromagnético. ${ }^{14} \mathrm{O}$ arranjo dos cátions produzem pares de octaedros de $\mathrm{Fe}(\mathrm{O}) 6$ que compartilham as bordas com três octaedros vizinhos e uma face com um octaedro em um plano adjacente, ${ }^{15}$ como mostrado na Figura 3. A hematita é o mais importante e mais abundante minério de ferro. ${ }^{10}$

\section{Goethita - $\alpha$-FeOOH}

A goethita, $\alpha-\mathrm{FeOOH}$, apresenta grupo pontual Pbnm e a célula unitária é ortorrômbica como mostrado na Figura 4. Os parâmetros de rede são $a=4,61 \AA b=9,96 \AA$ e $c=3,02 \AA .{ }^{16}$ A goethita é quimicamente constituída de $\mathrm{Fe}^{3+}$ dispostos de forma octaédrica coordenados a três átomos de $\mathrm{O}$ e três grupos $\mathrm{OH}^{-}$. A célula unitária contém 4 fórmulas químicas. O sistema é antiferromagnético, com alternância de spins antiparalelos, alinhados entre os planos ao longo do eixo $c$.
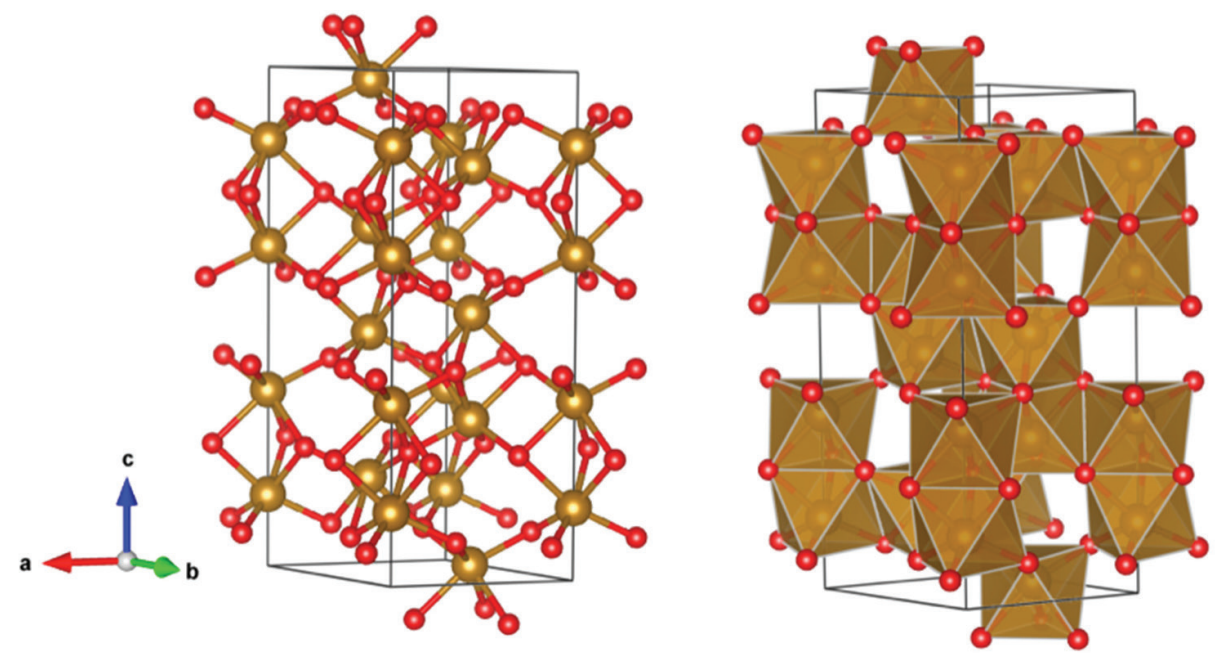

Figura 3. Estrutura da hematita. Ferro está com a cor marrom e o oxigênio de vermelho
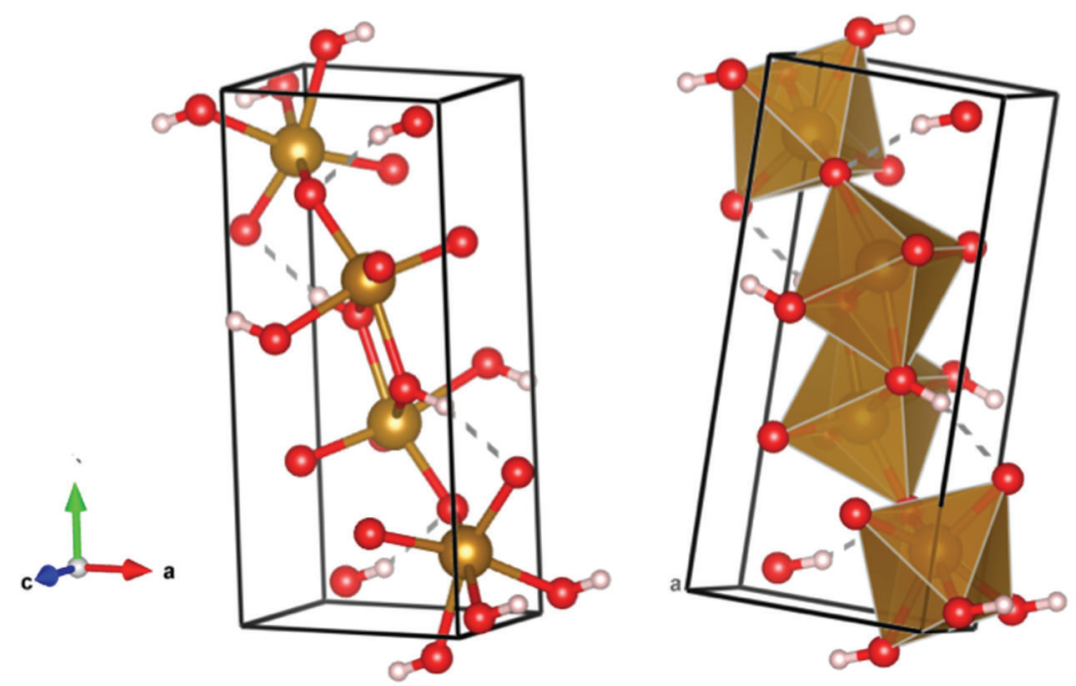

Figura 4. Estrutura da goethita. O ferro está com a cor marrom e o oxigênio de vermelho 


\section{Magnetita $-\mathrm{Fe}_{3} \mathrm{O}_{4}$}

A estrutura da magnetita, $\mathrm{Fe}_{3} \mathrm{O}_{4}$, é um espinélio invertido, ${ }^{17} \mathrm{com}$ uma célula unitária cúbica de face centrada mostrada na Figura 5. A célula unitária apresenta o parâmetro de rede $\mathrm{a}=8,39 \AA$ $\mathrm{com} 8$ fórmulas químicas. ${ }^{18} \mathrm{~A}$ magnetita é um óxido de ferro de valência mista contendo $\mathrm{Fe}^{2+}$ e $\mathrm{Fe}^{3+}$. Oito sítios tetraédricos são ocupados por $\mathrm{Fe}^{3+}$ e oito sítios octaédricos são ocupados por $\mathrm{Fe}^{2+} \mathrm{e}$ os outros $8 \mathrm{Fe}^{3+}$, ou seja, os íons de $\mathrm{Fe}^{3+}$ ocupam sítios octaédricos e tetraédricos. ${ }^{19} \mathrm{~A}$ magnetita é geralmente não-estequiométrica com deficiência de $\mathrm{Fe}^{3+}$. $\mathrm{O}$ íon $\mathrm{Fe}^{2+}$ pode também ser substituído por outros íons divalentes como $\mathrm{Mn}^{2+}$ e $\mathrm{Zn}^{2+}$.

\section{Pirita $-\mathrm{FeS}_{2}$}

A pirita, $\mathrm{FeS}_{2}$, é o mineral mais importante da classe dos sulfetos. Não é encontrado no minério de ferro. A pirita é uma preocupação ambiental principalmente nas regiões de mineração de ouro, urânio, cobre, entre outros metais nobres. O mineral é conhecido como "ouro dos tolos", devido a sua cor amarela metálica; cristaliza no sistema cúbico de face centrada, pertence ao grupo espacial Pa3 $(\# 205)^{20} \mathrm{e}$ tem parâmetro de rede $\mathrm{a}=5,418 \AA \AA^{21} \mathrm{Na}$ célula unitária, encontram-se quatro unidades de $\mathrm{FeS}_{2}$ (Figura 6). Sua estrutura pode ser melhor compreendida comparando-se seu empacotamento cristalino com o do $\mathrm{NaCl}$. A partir da estrutura iônica do $\mathrm{NaCl}$, trocando-se os íons $\mathrm{Na}^{+}$por $\mathrm{Fe}^{2+}$, e cada um dos ânions $\mathrm{Cl}^{-}$por $\mathrm{S}_{2}{ }^{2-}$, é possível representar o arranjo cristalino da pirita. Na estrutura da pirita todos os átomos de ferro estão ligados a seis átomos de enxofre formando um arranjo octaédrico. Cada átomo de enxofre está ligado a três átomos de ferro e um átomo de enxofre, formando sítios tetraédricos. A pirita possui apenas duas ligações

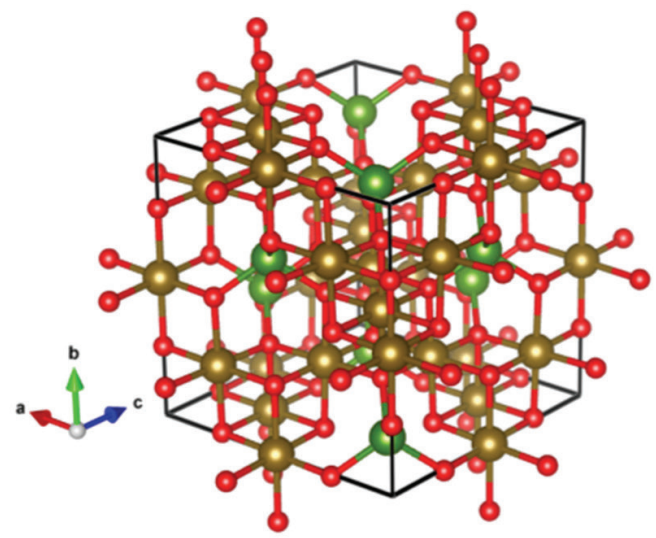

distintas: Fe-S e S-S. As ligações Fe-S são, por simetria, equivalentes e, da mesma forma, as ligações $\mathrm{S}-\mathrm{S}$ dos dímeros $\mathrm{S}_{2}{ }^{2-}$.

\section{Ocorrência}

O Brasil tem a quinta maior reserva de ferro do Globo; são as mais puras, em termos de ferro contido. ${ }^{22} \mathrm{O}$ Brasil está entre os três maiores países produtores de minério de ferro juntamente com a China e a Austrália. As reservas de ferro no Brasil estão localizadas principalmente no Estado de Minas Gerais, envolvendo as regiões do Quadrilátero Ferrífero, Vale do Rio Peixe Bravo, Bacia do Rio Santo Antônio; no Estado do Pará, na região dos Carajás; em Caetité, no sul do Estado da Bahia, e no Estado de Mato Grosso do Sul, na região de Morraria de Urucum.

O Quadrilátero Ferrífero localiza-se na porção centro-sul de Minas Gerais e corresponde à principal região produtora de minério de ferro do país com a predominância de hematita. Essa posição será ultrapassada pela região dos Carajás, Pará, atualmente a segunda maior região produtora de minério de ferro do país e de onde se extrai o minério de melhor qualidade do mundo, com predominância de hematita e quantidade significativa de magnetita. ${ }^{23}$

\section{BENEFICIAMENTO DO MINÉRIO DE FERRO}

O minério de ferro é composto do mineral de ferro (hematita, goethita ou magnetita) e da ganga, geralmente composto de silicatos. A Figura 7 mostra a fotomicrografia de uma amostra de itabiritos das Minas de Alegria da Samarco Mineração S. A., em Minas Gerais. A rocha é constituída principalmente de goethita, caulinita e gibbsita. A hematita ocorre nessa amostra em baixa concentração $(<15 \%)$.

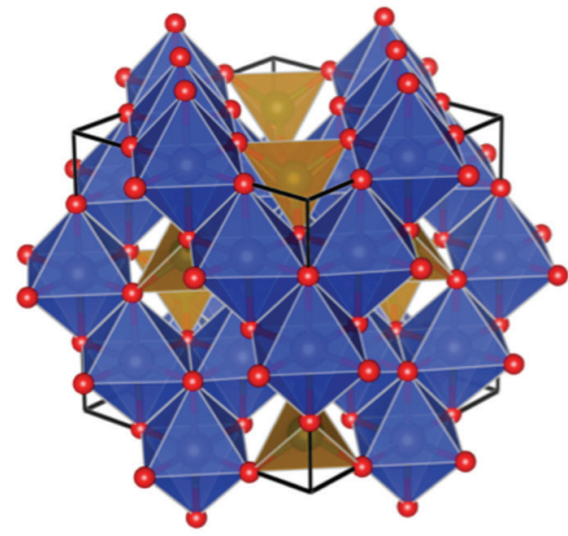

Figura 5. Estrutura da magnetita. Sítios de ferro tetraédricos estão em verde, octaédricos em marrom. O ferro está com a cor marrom e o oxigênio de vermelho
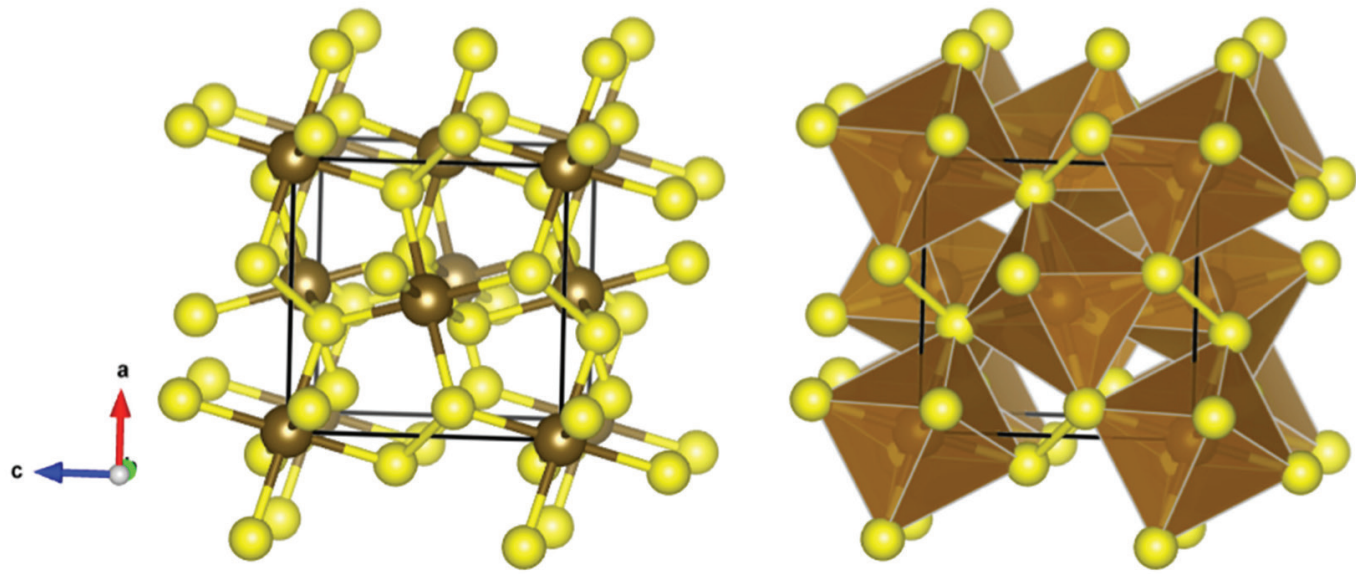

Figura 6. Estrutura da pirita. O Ferro está em marrom e o enxofre em amarelo 
Como a rocha é composta de diferentes minerais, o minério de ferro precisa passar por beneficiamento de forma a enriquecer o minério do mineral de interesse. Dessa forma o minério se torna apto para ser usado na siderurgia.

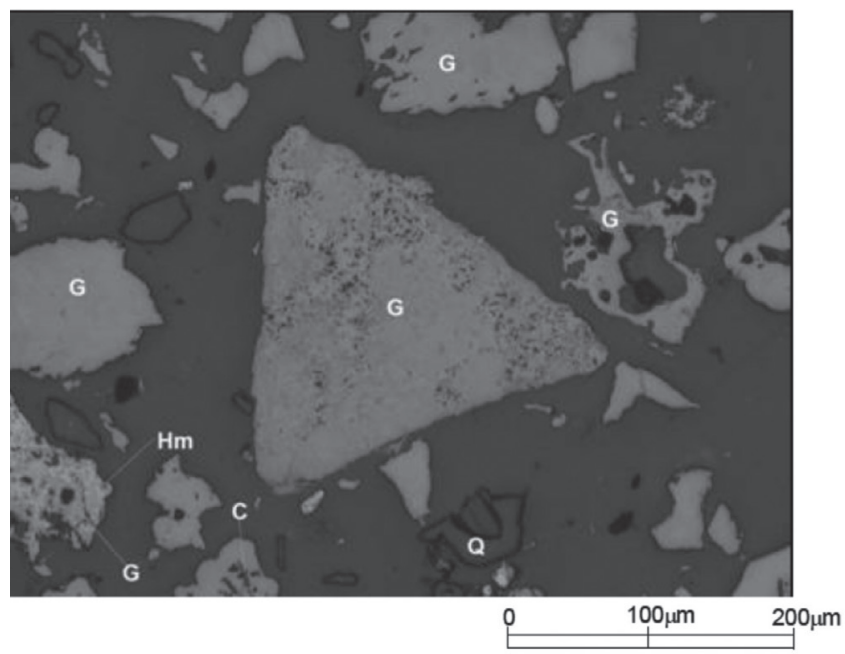

Figura 7. Fotomicrografia de uma amostra de minério de ferro. $G$ - goethita, $C$ - caulinita, $Q$ - quartzo, Hm - hematita. Reproduzido com permissão da Ref. 24

A Figura 8 representa um diagrama típico de tratamento de minério. O processo envolve operações unitárias clássicas ${ }^{25}$ que podem ser classificadas da seguinte forma:

- Britagem e moagem: tratam-se de operações que envolvem grande consumo de energia. Apesar dos estudos e avanços tecnológicos, ainda constitui em uma etapa necessária e pouco eficiente do ponto de vista energético.
- Classificação por peneiramento, hidrociclones ou classificador espiral: etapa necessária para separar os sólidos com diferentes granulometrias. A fração mais grosseira é reenviada para a britagem ou moagem. A escolha da melhor rota de classificação está relacionada, dentre outros fatores, com a faixa de granulometria do sólido.

- Concentração: trata-se da operação para separação do mineral desejado, de valor econômico (mineral-minério), que irá gerar o concentrado, da ganga, que irá constituir o rejeito. Utilizam-se diferentes processos, como os gravíticos, eletrostáticos, por flotação, entre outros, que se fundamentam em propriedades físico-químicas diferenciadoras dos minerais a serem separados.

- Desaguamento: etapa que envolve decantação, espessamento e filtragem do concentrado e rejeito, com recuperação de água para o processo.

- Disposição do rejeito em barragens de rejeito, cavas de mina ou galerias subterrâneas: trata-se de uma etapa crítica para minimizar impactos e riscos ambientais.

A rocha é composta de diferentes minerais (Figura 7). O processo de cominuição (britagem e moagem) irá reduzir o tamanho dos sólidos que vêm das minas, até o correspondente à etapa seguinte de concentração. Nessa etapa, é feita a separação das partículas do mineral de interesse utilizando-se alguma propriedade que as distingam dos minerais de ganga. Por exemplo, a diferença de densidade pode ser utilizada em processos gravíticos. As propriedades das superfícies dos minerais podem ser ajustadas pela adição de reagentes, para permitir a separação via flotação. Propriedades magnéticas podem ser também utilizadas para separar os diferentes minerais.

Todos estes processos são dimensionados para se trabalhar com milhões de toneladas/ano e requerem espaço e disponibilidade de água. Em geral, parte da água proveniente do rebaixamento do lençol freático durante aprofundamento da cava da mina é utilizada na usina

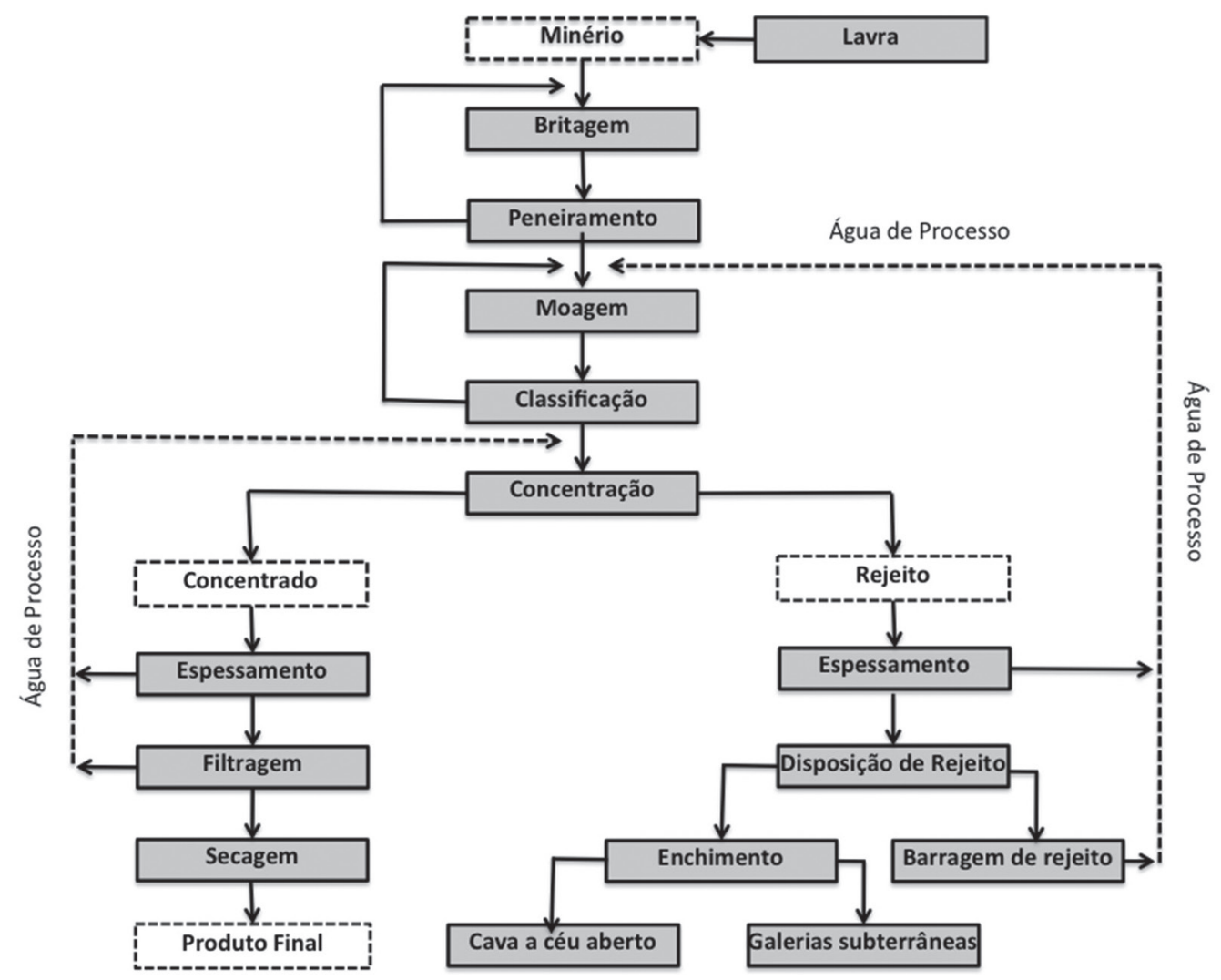

Figura 8. Diagrama típico de tratamento de minério. Adaptado da Ref. 26 
de beneficiamento. Ao final, é preciso recuperar a água utilizada, para ser reaproveitada no processo, minimizando o consumo de água nova. A diminuição do conteúdo de água nos rejeitos é importante para diminuir o consumo da água na usina e assim contribuir para a disponibilidade hídrica na região, mas também para aumentar a segurança das barragens de rejeito. A disposição a seco de resíduos é uma tendência crescente no beneficiamento dos minérios.

\section{VALORAÇÃO DO MINÉRIO DE FERRO}

A produção bruta do minério de ferro (em toneladas anuais de minério) no Brasil está praticamente concentrada nos Estados de Minas Gerais $(69,6 \%)$ e Pará $(28,8 \%)$ com teor médio de ferro de $50,34 \%$ e $65,46 \%$, respectivamente, segundo dados de 2017. Ainda nesse ano, foram beneficiados cerca de 453 milhões de toneladas de minério correspondendo ao valor de 88 bilhões de reais (cerca de 28 bilhões de dólares). A companhia VALE é responsável por 79,17\% da produção de minério de ferro no Brasil. Outras oito empresas atuam no mercado brasileiro e são responsáveis por cerca de $20 \%$ da produção de minério de ferro do país. ${ }^{27}$

$\mathrm{Na}$ pauta de exportações brasileiras, $8,8 \%$ referem-se a substâncias metálicas; $68 \%$ deste valor correspondem a ferro (incluindo materiais primários e manufaturados). ${ }^{9}$ Os outros metais em destaque são cobre, alumínio, ouro e nióbio, que correspondem a 8,8\%; 7,7\%; $6,7 \%$ e $4,3 \%$, respectivamente, das exportações de substâncias metálicas conforme mostra a Figura 9. De acordo com o Anuário Mineral Brasileiro, ${ }^{27}$ em 2017, 67\% da exportação mineral corresponderam a bens primários. Ou seja, apenas $33 \%$ da exportação corresponderam a produtos semimanufaturados ou manufaturados.

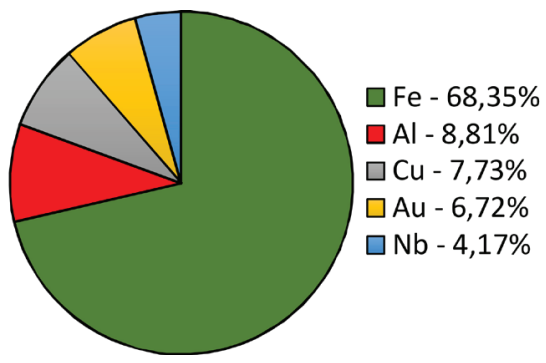

Figura 9. Distribuição dos principais metais na pauta de exportações brasileiras de substâncias metálicas. Fonte: Camara de Comércio do Exterior ${ }^{9}$
A disponibilidade de minério de ferro com alto teor é uma vantagem econômica para a sua industrialização e a produção de aço. No entanto, há um excesso da capacidade de produção global de aço em cerca de 736 milhões de toneladas, sendo que cerca de 405 milhões estão na China. ${ }^{28} \mathrm{O}$ Brasil produz o equivalente a $1,9 \%$ da produção internacional de aço, correspondendo a $54 \%$ do total produzido na América Latina, o que sustenta uma posição de liderança nesta região. De acordo com a Confederação Nacional das Indústrias (CNI), as indústrias metalúrgicas nacionais operaram com cerca de $63 \%$ da capacidade instalada em 2017. ${ }^{28} \mathrm{~A}$ análise desses dados indica que há uma capacidade de produção de aço ociosa ao nível mundial. No entanto, nos países emergentes, como o Brasil, a sua produção corresponde a meros $2 \%$ da produção mundial. Isso explica a tradição brasileira de exportar o ferro na sua forma de minério. A produção de aço na América Latina é muito pequena e, estrategicamente, o Brasil deve buscar mercados fora do eixo USA-Europa-China para elevar a utilização da capacidade instalada de produção de aço do país.

O minério de ferro é uma commodity importante como o petróleo, soja, milho e açúcar, dentre outros. Ou seja, a produção global de minério de ferro é da ordem de 2,5 bilhões de toneladas por ano: ${ }^{29} \mathrm{o}$ preço e a demanda são governados pelo mercado mundial. A utilização do aço é intensiva na construção civil, nas indústrias mecânica, automobilística, entre outras áreas. Em um período de estagnação da economia como a que estamos passando, ampliar o mercado de aço não é uma tarefa fácil, principalmente levando-se em conta a dimensão do mercado e a sua competitividade. Por outro lado, encontrar novos nichos nos quais o aço produzido no Brasil possa ser usado passa, por exemplo, pela agregação de valor e pela produção- por exemplo, de materiais especiais para aplicações específicas.

\section{Produção de aço}

A Figura 10, mostra, de forma simplificada, o processamento do minério de ferro até a fabricação do aço líquido. O detalhamento do beneficiamento do minério de ferro é mostrado na Figura 8. O minério de ferro beneficiado e com a granulometria adequada é utilizado nos altos-fornos para a produção do ferro gusa (com alto teor de carbono). A parte do minério de ferro beneficiado que se encontra com granulometria não adequada, por exemplo, com elevada quantidade de finos, é encaminhada para os processos de sinterização ou pelotização. Tratam-se de processos de aglomeração que visam obter

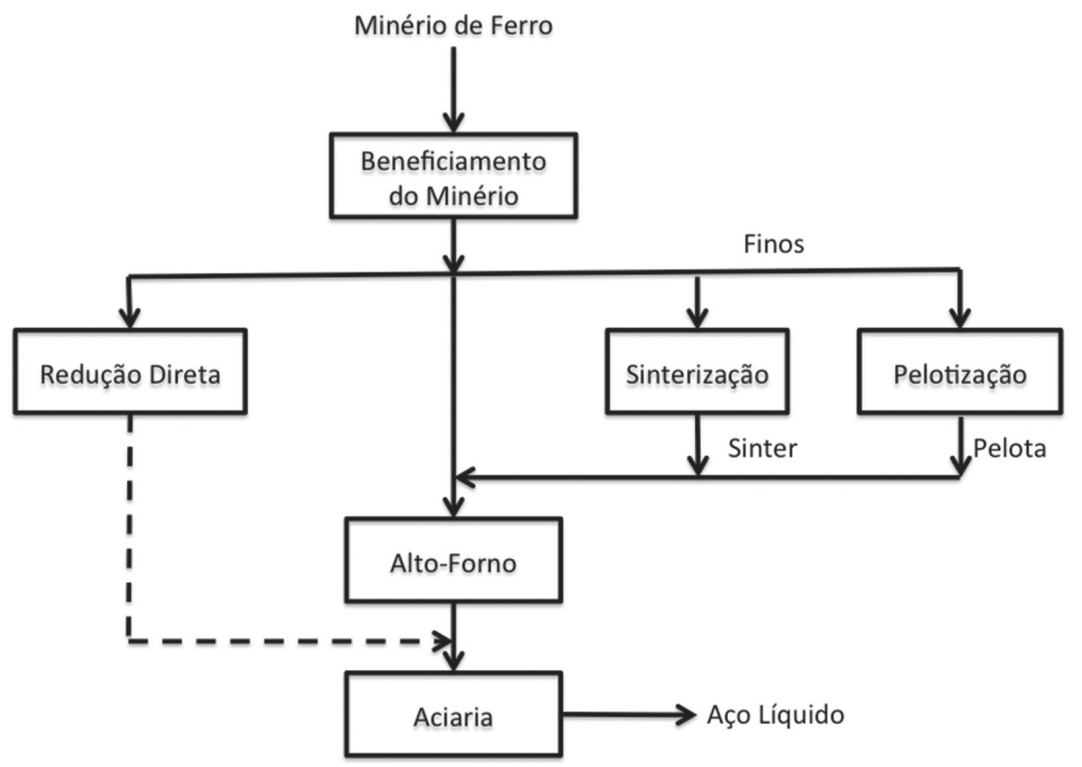

Figura 10. Processamento básico do minério de ferro para a fabricação de aço líquido 
o material em granulometria adequada para o seu processamento em altos-fornos. A sinterização e a pelotização envolvem tratamento térmico entre 1000 e $1200^{\circ} \mathrm{C}$.

O minério (ou sínter) com a granulometria adequada é levado ao alto-forno, juntamente com os redutores e fundentes para a produção do ferro-gusa, contendo aproximadamente $94 \%$ de ferro, $4 \%$ de carbono e o restante de elementos que dependem da matéria prima utilizada. A escória é outro produto constituído dos fundentes utilizados $(\mathrm{CaO}$ e $\mathrm{MgO})$, da ganga proveniente do minério (geralmente aluminosilicatos) e das cinzas do carvão. Por ser menos densa que o ferro-gusa líquido, a sua separação é feita por densidade.

O ferro-gusa é matéria prima da aciaria onde, por meio da redução dos teores de carbono e outras impurezas, é transformado em aço. A remoção das impurezas ocorre principalmente por meio da injeção de oxigênio no ferro-gusa líquido levando à oxidação controlada das impurezas (processo LD) e sua remoção para a escória. O aço líquido é, então, conduzido para o lingotamento que consiste na sua solidificação em lingotes que serão destinados a aplicações específicas.

\section{CONSIDERAÇÕES FINAIS}

Uma das características da extração de minério de ferro no Brasil, em especial no Quadrilátero Ferrífero, Minas Gerais, é a proximidade com áreas urbanas. Conflitos crescentes com relação à disponibilidade hídrica, ${ }^{30}$ qualidade ambiental ${ }^{31}$ e a gestão de riscos ${ }^{32}$ têm dificultado a denominada "licença social" da atividade de mineração na região. A construção de uma abordagem em que os impactos da atividade mineral sejam minimizados é uma necessidade premente, enquanto os lucros da extração de um recurso natural finito que promovam a construção da prosperidade sustentável da região não for uma realidade. $\mathrm{O}$ aproveitamento dos rejeitos em aplicações secundárias carece de articulação com outras cadeias produtivas, como, por exemplo, da indústria cimenteira e da construção civil, mas, também, da viabilidade econômica. Políticas públicas devem ser criadas para as regiões mineradoras; a regulamentação e a implementação geridas por órgãos específicos devem sustentar as boas práticas internalizadas no planejamento físico-financeiro das empresas.

A competitividade das atividades mineradoras/metalúrgicas é cada vez mais dependente da aprovação da sociedade. A indústria é chamada a responder positivamente a esses interesses, com abordagens abrangentes, que permitam lidar com as complexas e múltiplas interfaces das atividades mineradoras, como bacias hidrográficas, aglomerados urbanos próximos, áreas protegidas e patrimônio cultural. O desafio cria, assim, oportunidades únicas para o desenvolvimento, tanto científico, quanto tecnológico e para a capacitação de recursos humanos. Novas ferramentas analíticas são fortemente requeridas para se avaliar os impactos ambientais e guiar iniciativas inovadoras para a recuperação de áreas impactadas. ${ }^{33}$ Os processos industriais devem ser reformulados para um melhor desempenho ambiental e, finalmente, informações relevantes devem ser disponibilizadas para todos os interessados. A busca de modelos que conciliem a atividade industrial com a conservação dos recursos hídricos, da biodiversidade e do patrimônio cultural é uma tendência observada em diversas partes do mundo. A construção de soluções específicas para cada região de mineração permite fortalecer as comunidades locais bem como a cadeia local de fornecedores de tecnologia e de conhecimento.

A extração do minério de ferro no país, pela sua magnitude e pelo protagonismo local, deve ser um eixo mobilizador de iniciativas dirigidas à inovação, ao desenvolvimento científico, à integração indústria-sociedade, à capacitação de recursos humanos e ao desenvolvimento regional sustentável. As universidades podem oferecer uma abordagem sistêmica, abrangente e interdisciplinar dos diferentes temas associados à extração de ferro, de forma a auxiliar o governo na formulação de políticas públicas adequadas a cada região, a atender às demandas da sociedade, por informações claras e confiáveis, e a auxiliar as empresas na busca de soluções inovadoras e no diálogo com o governo e a sociedade. ${ }^{34-36}$

\section{AGRADECIMENTOS}

Agradeço imensamente pelas discussões frutíferas com a Profa Virgínia S. T. Ciminelli e pela leitura do texto. Agradeço também o auxílio da Dra Cláudia L. Caldeira na confecção do diagrama de Pourbaix e ao Prof. Heitor A. De Abreu com a elaboração do resumo gráfico. Estou, ainda, grato pelo apoio financeiro do Instituto Nacional de Ciência e Tecnologia para Recursos Minerais, Água e Biodiversidade (INCT-Acqua, http://www.acqua-inct.org), FAPEMIG (Proc. REDE-00102-16) e CNPq.

\section{REFERÊNCIAS}

1. Mason, B.; Moore, C. B., Principles of Geochemistry, $4^{\text {th }}$ ed., Wiley: New York, 1982.

2. Martell, A. E.; Smith, R. M.; Motekaitis, R. J.; Critically Selected Stability Constants of Metal Complexes, College Station, 1997, vol. 46.

3. Lide, D. R., Crc Handbook of Chemistry and Physics, CRC Press: Boca Raton, 2005.

4. Ladeira, A. C. Q.; Paniago, E. B.; Duarte, H. A.; Caldeira, C. L.; Quim. Nova Esc. - Cadernos Temáticos 2014, 8, 18.

5. Guimaraes, C. M.; Symanski, L. C. P.; De Souza, M. A. T., Em Geossistemas Ferruginosos Do Brasil; Do Carmo, F. F., Kamino, L. H. Y., eds.; Pristino: Belo Horizonte, 2015; p. 543.

6. Pelaez, C. M.; Revista Brasileira de Economia - FGV 1970, 24, 191.

7. http://brasil.aperam.com/, acessada em outubro 2019.

8. Centro de Pesquisa e Documentação de História Contemporânea do Brasil - FGV, https://cpdoc.fgv.br/producao/dossies/AEraVargas1/ anos37-45/EstadoEconomia/CVRD, acessada em outubro 2019.

9. http://www.mdic.gov.br/comercio-exterior/estatisticas-de-comercioexterior/comex-vis/frame-brasil, acessada em outubro 2019.

10. Klein, C.; Dutrow, B.; Manual de Ciências dos Minerais, $23^{\mathrm{a}}$ ed., Bookman: New York, 2012, p. 718.

11. Peng, S.; Yu, L.; Sun, M.; Cheng, G.; Lin, T.; Mo, Y.; Li, Z.; J. Power Sources 2015, 296, 237.

12. De Mello, J. W. V.; Duarte, H. A.; Ladeira, A. C. Q.; QNEsc - Caderno Temático 2014, 8, 24-29.

13. Blake, R. L.; Hessevick, R. E.; Zoltai, T.; Finger, L. W.; Am. Mineral. 1966, 51 (1-2), 123-124.

14. Morin, F. J.; Phys. Rev. 1950, 78, 819.

15. Cornell, R. M.; Schwertmann, U.; The Iron Oxides - Structure, Properties, Reactions, Occurrence and Uses, VCH: Weinheim, 1996, p. 558.

16. Sampson, C. F.; Acta Crystallogr. B 1969, B 25, 1683.

17. Hill, R. J.; Craig, J. R.; Gibbs, G. V.; Phys. Chem. Miner. 1979, 4, 317.

18. Bragg, W. H.; Nature 1915, 95, 561.

19. Walz, F.; J. Phys.: Condens. Matter 2002, 14, R285.

20. Bragg, W. H.; Bragg, W. L.; Proc. R. Soc. A 1913, 88, 428.

21. Brostigen, G.; Kjekshus, A.; Astrup, E. E.; Nordal, V.; Lindberg, A. A.; Craig, J. C.; Acta Chem. Scand. 1969, 23, 2186.

22. Centro de Gestão e Estudos Estratégicos; Siderurgia No Brasil - 20102025. Centro de Gestão e Estudos Estratégicos: Brasilia, 2010, vol. 9.

23. Do Carmo, F. F.; De Souza, M. A. T. Em Geossistemas Ferruginosos do Brasil, Do Carmo, F. F., Kamino, L. H. Y., eds.; Pristino: Belo Horizonte, 2015, p. 543.

24. Rocha, J. M. de P.; Tese de Doutorado, Universidade Federal de Minas Gerais, Belo Horizonte, 2008. 
25. de Morais, C. A.; de Albuquerque, R. O.; Ladeira, A. C. Q.; Quim. Nova Esc. - Cadernos Temáticos 2014, 8, 9.

26. De Castro, L. F. A.; Figueira, R. M.; Tavares, R. P.; Princípios Básicos E Processos De Fabricação Do Gusa E Aço Líquido, Editora UFMG: Belo Horizonte, 2004, p. 250.

27. Ferreira Filho, O. B.; Anuário Mineral Brasileiro: Principais Substâncias Metálicas - Ano Base 2017, Agência Nacional de Mineração: Brasília, 2019.

28. Lopes, M. P. de M.; A Indústria Do Aço No Brasil, Confederação Nacional da Indústria - CNI: São Paulo, 2017.

29. U.S. Geological Survey, Mineral Commodity Summaries, U.S. Geological Survey, 2019, p. 200.

30. Ciminelli, V. S. T.; Barbosa, F. Em Ângulos Da Água, $1^{\mathrm{a}}$ ed.; Barbosa, F., Blakemore, H. J., eds.; Editora UFMG: Belo Horizonte, 2008, Vol. 1.

31. Tavares, F. V. F.; Ardisson, J. D.; Rodrigues, P. C. H.; Fabris, J. D.; Fernandez-Outon, L. E.; Feliciano, V. M. D.; Environ. Sci. Pollut. Res. 2017, 24, 19683.

32. Domingues, A. F.; Boson, P. H. G.; Alípaz, S.; A Gestão dos Recursos Hídricos e a Mineração, Agência Nacional de Águas: Brasília, 2006.

33. Ciminelli, V. S. T.; Barbosa, F. A. R.; Tundsi, J. G.; Duarte, H. A.; Quím. Nova Esc. - Cadernos Temáticos 2014, 8, 39.
34. Ladeira, A. C. Q.; Ferreira, A. M.; Caldeira, C. L.; Barbosa, F. A. R.; Duarte, H. A.; Ribeiro, I.; Mello, J. W. V.; Tundisi, J. G.; Ciminelli, V. S. T.; Activity Report - INCT - Acqua - Recursos Minerais, Água e Biodiversidade, Universidade Federal de Minas Gerais: Belo Horizonte, 2009-2010, p. 85, disponível em http://acqua-inct.org, acessada em outubro 2019.

35. Ladeira, A. C. Q.; Ferreira, A. M.; Caldeira, C. L.; Barbosa, F. A. R.; Duarte, H. A.; Ribeiro, I.; Mello, J. W. V.; Tundisi, J. G.; Ciminelli, V. S. T.; Activity Report - INCT - Acqua - Recursos Minerais, Água e Biodiversidade, Universidade Federal de Minas Gerais: Belo Horizonte, 2011-2012, p 104, disponível em http://acqua-inct.org, acessada em outubro 2019.

36. Ladeira, A. C. Q.; Ferreira, A. M.; Caldeira, C. L.; Barbosa, F. A. R.; Duarte, H. A.; Ribeiro, I.; Mello, J. W. V.; Tundisi, J. G.; Ciminelli, V. S. T.; Activity Report - INCT - Acqua - Recursos Minerais, Água e Biodiversidade, Universidade Federal de Minas Gerais: Belo Horizonte, 2013-2016, p. 116, disponível em http://acqua-inct.org, acessada em outubro 2019. 